Hal. 1 - 11

\title{
PENGARUH BUDAYA ORGANISASI DAN GAYA KEPEMIMPINAN TERHADAP KEPUASAN KERJA DAN KINERJA KARYAWAN DI LINGKUNGAN KANTOR PUSAT UNIVERSITAS JEMBER
}

\author{
Budi Prasetiyo \\ Program Pasca Sarjana Program Studi Magister Manajemen Universitas \\ Jember \\ bupras_67@yahoo.com
}

\begin{abstract}
Employee contribution becomes important when it is done with effective action and right behavior. Not only the amount of effort but also the direction of the business. The nature, effort or willingness to work as well as the various things that constitute organizational support is very important for the success of employee performance. In this study, the author tries to analyze the problems faced by the administrative staff of Jember University (UNEJ). Empirical tests were conducted on 115 administrative employees to obtain data on organizational culture and leadership style that has been enough to give hope to the administrative staff. Analyzer used in this research is Structural Equation Model (SEM). From the results of model testing, it can be concluded that organizational culture and leadership style have a positive effect on job satisfaction, leadership style positively affect the organizational culture. Organizational culture, leadership style, and job satisfaction have a positive effect on employee performance. To improve the performance of administrative employees, especially the dimensions of cost control and self-reliance initiatives, it requires a bureaucratic leadership style and autocratic leadership style in an open and process-oriented organizational culture system as an effort to improve employee job satisfaction.
\end{abstract}

Keywords: Organizational Culture, Leadership Style, Job Satisfaction, and Employee Performance

Abstrak: Kontribusi karyawan akan menjadi penting apabila dilakukan dengan tindakan efektif dan berperilaku secara benar. Tidak hanya jumlah usaha tetapi juga arah dari usaha. Sifat-sifat, upaya atau kemauan untuk bekerja serta berbagai hal yang merupakan dukungan organisasi sangat besar artinya bagi keberhasilan kinerja karyawan. Dalam penelitian ini menganalisis permasalahan yang dihadapi karyawan administratif Universitas Jember (UNEJ), Uji empiris dilakukan terhadap 115 karyawan administratif guna mendapatkan data tentang budaya organisasi dan gaya kepemimpinan yang selama ini cukup dapat memberikan harapan bagi karyawan administrarif. Alat analisis yang digunakan dalam penelitian ini adalah Structural Equation Model (SEM). Dari hasil pengujian model, dapat disimpulkan budaya organisasi dan gaya kepemimpinan berpengaruh positif terhadap kepuasan kerja, gaya kepemimpinan berpengaruh positif terhadap budaya organisasi. Budaya organisasi, gaya kepemimpinan, dan kepuasan kerja berpengaruh positif terhadap kinerja karyawan. Untuk memperbaiki kinerja karyawan administratif terutama dimensi terhadap pengendalian biaya-biaya dan inisiatif kemandirian maka diperlukan gaya kepemimpinan birokratis dan gaya kepemimpinan autokratis dalam suasana budaya organisasi sistim terbuka dan berorientasi pada proses sebagai upaya untuk meningkatkan kepuasan kerja karyawan.

Kata kunci : Budaya Organisasi, Gaya Kepemimpinan, Kepuasan Kerja dan Kinerja Karyawan. 


\section{Pendahuluan}

Organisasi merupakan kesatuan sosial yang dikoordinasikan secara sadar, dengan sebuah batasan yang relatif dapat diidentifikasi, bekerja secara terus menerus untuk mencapai tujuan (Robbins, 2001:79). Secara eksplisit, definisi tersebut mengasumsikan kebutuhan untuk mengkoordinasikan pola interaksi manusianya. Pola interaksi sumber daya manusia dalam organisasi harus diseimbangkan dan diselaraskan agar organisasi dapat tetap eksis. Permasalahan yang berkaitan dengan sumber daya manusia dalam suatu organisasi menuntut untuk diperhatikan, sebab secanggih apapun teknologi yang dipergunakan dalam suatu organisasi serta sebesar apapun modal organisasi, karyawan dalam organisasilah yang pada akhirnya yang menjalankan. Hal ini menunjukkan bahwa tanpa didukung dengan kualitas yang baik dari karyawan dalam melaksanakan tugasnya keberhasilan organisasi tidak tercapai. Kontribusi karyawan pada suatu organisasi akan menentukan maju atau mundurnya organisasi. Kontribusi karyawan pada organisasi akan menjadi penting, jika dilakukan dengan tindakan efektif dan berperilaku secara benar.

Universitas Jember mempunyai visi menjadi universitas unggul dalam pengembangan sains, teknologi dan seni berwawasan lingkungan, bisnis, dan pertanian industrial. Adapun penelitian ini termotivasi oleh beberapa fenomena di Lingkungan Kantor Pusat Universitas Jember, bahwa peneliti menduga adanya perbedaan kultural, seperti perilaku dalam kehidupan sehari-hari, Keadaan tersebut tidak bisa dibiarkan terus menerus oleh pihak manajemen, karena nantinya bila dibiarkan akan mengarah kepada tindakan-tindakan : karyawan tidak loyal, karyawan mengabaikan seperti mangkir atau datang terlambat, mengurangi kualitas dan kuantitas kerja serta tingkat kesalahan pekerjaan meningkat (Robbins, 2001).

Pada akhirnya berdampak pada kinerja yang menurun, dengan demikian penelitian ini diharapakan dapat mencerminkan hasil kinerja karyawan. Selain itu alasan lain adalah dengan melihat adanya salah satu masalah nasional yang dihadapi oleh bangsa Indonesia saat ini adalah masalah penanganan terhadap rendahnya kualitas sumber daya manusia. masalah budaya organisasi, motivasi kerja dan gaya kepemimpinan, kepusan kerja serta kinerja pegawai juga merupakan masalah yang esensial bagi suatu organisasi maupun perusahaan. Jumlah sumber daya manusia yang besar apabila digunakan secara efektif dan efisien, hal ini akan bermanfaat untuk menunjang gerak lajunya pembangunan nasional yang berkelanjutan. 
Penelitian yang dilakukan oleh Shea (1999), yang meneliti pengaruh gaya kepemimpinan pada peningkatan kinerja kualitatif dan kuantitatif pada bidang manufaktur sepanjang waktu. Dari hasil pembahasan untuk pemimpin yang menggunakan gaya perbandingan secara terus-menerus memiliki kualitas output yang lebih tinggi daripada mereka yang bekerja dibawah gaya kepemimpinan terstruktur atau gaya kharismatik. Penemuan ini mengindikasikan bahwa dengan berpusat pada kenyamanan dan pengetahuan yang baik dari karyawan, pemimpin dengan gaya perbandingan mungkin membantu mereka untuk beristirahat dan bekerja lebih cepat daripada pemimpin dengan gaya terstruktur yang menekankan jumlah pekerjaan untuk dapat diselesaikan dan jumlah waktu yang disediakan.

Studi ini mendukung pernyataan bahwa gaya kepemimpinan memiliki pengaruh pada peningkatan kinerja sepanjang waktu. Penelitian yang dilakukan oleh Soonhee Kim (2002), hasil dari analisis multiple regression memperlihatkan bahwa penggunaan gaya manajemen partisipatif oleh manajer secara positif dihubungkan dengan tingkat yang tinggi dari kepuasan kerja. Dengan memperhatikan kinerja organisasi dan produktifitas individu, ketidakhadiran dan peringatan adalah target signifikan untuk manajemen sumber daya manusia baik dalam sektor publik maupun swasta. Banyak manajer, pemimpin perserikatan dan akademisi membagi kepercayaan bahwa praktek manajemen partisipatif mempunyai pengaruh positif yang substansial terhadap kinerja dsn kepuasan dalam pekerjaan (Jackson, 1983; Bluestone dan Bluestone. 1992; Berrstein, 1993), dalam Soonhee Kim, 2002).

Penelitian yang dilakukan oleh Harris dan Ogbonna (2001), dari ketiga gaya kepemimpinan yang dianalisis ditemukan gaya kepemimpinan partisipatif menduduki peringkat pertama dalam hubungan dengan orientasi pasar. Peringkat kedua adalah gaya kepemimpinan supportif dan peringkat ketiga adalah gaya kepemimpinan instrumental. Korelasi antara ketiga gaya kepemimpinan dengan orientasi pasar menunjukkan hubungan yang monoton. Gaya kepemimpinan partisispatif dan supportif secara positif dan signifikan berhubungan dengan orientasi pasar. Temuan ini mengindikasikan bahwa sebuah gaya kepemimpinan dicirikan oleh perilaku pemimpin yang diarahkan kepada harapan yang terukur, alokasi tugas dan penetapan prosedur.

Maka dari itu, disusun hipotesis sebagai berikut: (1) $\mathrm{H} 1$ : Budaya Organisasi berpengaruh terhadap kepuasan kerja Karyawan; (2) H2 : Gaya Kepemimpinan berpengaruh terhadap kepuasan kerja Karyawan; (3) H3 : Budaya Organisasi 
berpengaruh terhadap kinerja; (4) H4 : Gaya Kepemimpinan berpengaruh terhadap kinerja; dan (5) H5 : Kepuasan Kerja berpengaruh terhadap Kinerja Karyawan.

\section{Metodologi}

Rencana penelitian ini dilakukan di Kantor Pusat Universitas Jember pada Bagian Umum Hukum dan Tata Laksana, Bagian Kepegawaian, Bagian Pendidikan dan Bagian Kemahasiswaan dimana penelitian ini mempunyai maksud menjelaskan pengaruh antara variabel melalui pengujian hipotesis dan sekaligus melakukan eksplanasi terhadap beberapa variabel maka rancangan penelitian ini adalah penelitian eksplanatori (explanatory research), yang merupakan jenis penelitian kuantitatif.

Estimated parameter dalam penelitian ini sejumlah 23 indikator, maka jumlah sampel yang diambil minimal 115 - 230 sampel, maka yang diambil sebagai sampel 115 karyawan karena menurut standar minimal sampel yang ideal dengan teknik analisis SEM menurut Sinaga (1994) bahwa untuk sampel yang sesuai adalah 100 200. Pengumpulan data dengan cara pengisian kuesioner dan dokumentasi.

\section{Hasil dan Pembahasan}

Secara garis besar penelitian ini menunjukkan secara umum hipotesis yang diajukan dapat diterima. Dalam hal ini terdapat pengaruh yang signifikan budaya organisasi dan gaya kepemimpinan terhadap kinerja baik secara langsung maupun tidak langsung melalui kepuasan kerja.

\section{Pengaruh Budaya Organisasi Terhadap Kepuasan Kerja}

Hasil analisis yang telah dilakukan menunjukkan bahwa budaya organisasi memiliki pengaruh yang signifikan positif terhadap kepuasan kerja yang dapat diartikan jika terjadi peningkatan persepsi terhadap budaya organisasi maka akan meningkat pula kepuasan kerja. Gibson (1996 : 42) mendefinisikan budaya organisasi sebagai suatu sistem nilai, keyakinan dan norma-norma yang unik dimiliki secara bersama oleh anggota suatu organisasi.

Budaya organisasi dapat menjadi kekuatan positif dan negatif dalam mencapai prestasi organisasi yang efektif. Kotter and Heskett (1997 : 5) menyatakan bahwa budaya dalam organisasi merupakan nilai yang dianut bersama oleh anggota organisasi, cenderung membentuk perilaku kelompok. Nilai-nilai sebagai budaya organisasi cenderung tidak terlihat maka sulit berubah. Sedangkan norma perilaku kelompok yang dapat dilihat, tergambar pada pola tingkah laku dan gaya anggota 
organisasi relatif dapat berubah, misalnya dengan memberikan imbalan bagi mereka yang dapat menyesuaikan diri, sebaliknya akan diberi sanksi bagi mereka yang tidak dapat menyesuaikan diri dengan organisasi.

Dari kedua definisi tersebut di atas, dapatlah disimpulkan bahwa budaya organisasi adalah keseluruhan sistem nilai, norma-norma, pola pikir dan perilaku serta keyakinan dan kebijaksanaan yang ditampilkan secara konsisten yang akan mempengaruhi pada kerja sama anggota organisasi serta manajemen organisasi. Budaya organisasi bertujuan meningkatkan kinerja dan kepuasan karyawan dalam organisasi. Dengan demikian dapat kita lihat bahwa kesimpulan dari hasil analisa tersebut dapat diterima.

\section{Pengaruh Gaya Kepemimpinan terhadap Kepuasan Kerja}

Hasil penelitian menunjukkan gaya kepemimpinan mempunyai pengaruh yang signifikan terhadap kepuasan kerja. Sehingga hipotesis yang menyatakan bahwa gaya kepemimpinan berpengaruh terhadap kepuasan kerja karyawan di lingkungan kantor pusat Universitas Jember terbukti kebenarannya atau $\mathrm{H} 2$ diterima.

Hal ini berarti perilaku pemimpin merupakan salah satu faktor penting yang dapat memengaruhi kepuasan kerja. Hubungan yang akrab tolong-menolong dengan teman sekerja serta dengan pemimpin adalah sangat penting dan memiliki hubungan kuat dengan kepuasan kerja, semakin baik pemimpin dalam membawahi karyawannya semakin nyaman dan puas juga para karyawan dalam melakukan pekerjaanya, begitu pula sebaliknya. Sehingga hal ini mendukung penelitian Miller et al. (1991 mengenai hubungan positif gaya kepemimpinan dengan kepuasan kerja.

Gaya kepemimpinan yang tepat akan mampu menciptakan lingkungan kerja yang kondusif bagi karyawan, hubungan kerja yang baik antara karyawan dengan atasan, hilangnya kesenjangan sosial antar lini dalam perusahaan, yang akan menciptakan suasana kerja yang nyaman bagi semua pihak termasuk karyawan. Karyawan akan merasa puas apabila bekerja dengan kondisi atau situasi yang baik sesuai dengan harapan karyawan tersebut. Setelah kepuasan kerja karyawan terpenuhi dengan baik, akan berpengaruh terhadap kinerja karyawan. Gaya kepemimpinan yang baik akan berpengaruh terhadap meningkatnya kepuasan kerja karyawan dan selanjutnya setelah karyawan merasa puas maka kinerja karyawan tersebut akan meningkat. Karyawan dengan tingkat kepuasan kerja yang tinggi karena 
gaya kepemimpinan yang tepat akan berpengaruh positif terhadap kinerja karyawan yang bersangkutan.

\section{Pengaruh Budaya Organisasi Terhadap Kinerja Karyawan}

Hasil penelitian menunjukkan bahwa ada pengaruh positif dan signifikan budaya organisasi terhadap kinerja karyawan di lingkungan kantor pusat Universitas Jember. Hal ini membuktikan hipotesis yang menyatakan ada pengaruh positif dan signifikan budaya organisasi terhadap kinerja karyawan.

Tahun 1980-an memberikan kesaksian mengenai gelombang popularitas untuk menguji konsep budaya organisasi sebagai manajer menjadi meningkatkan kesadaran akan jalan dimana budaya organisasi dapat mempengaruhi karyawan dan organisasi (Daulatram 2003). Perembesan budaya organisasi membutuhkan pengenalan manajemen dimensi dasar dari budaya organisasi mereka dan pengaruhnya pada varibel yang berkaitan dengan karyawan seperti kepuasan, komitmen, kohesi, implementasi strategi, kinerja dan yang lain.

Harriss dan Mossholder (1996), bahwa budaya organisasi berdiri sebagai pusat dari seluruh faktor yang berasal dari manajemen sumber daya manusia. Budaya organisasi dipercaya mempengaruhi setiap individu mengenai hasil seperti komitmen, motivasi, moral dan kepuasan. Sedangkan Wallach (1983), menunjukkan bahwa kinerja karyawan dalam hasil kerja yang menyenangkan termasuk kepuasan kerja, cenderung untuk tinggal dalam organisasi dan keterlibatan kerja, tergantung pada kecocokan antara karakteristik individu dan budaya organisasi.

Budaya organisasi merupakan variabel kunci yang bisa mendorong keberhasilan perusahaan. Meski tidak sepenuhnya benar, bahwa perusahaan yang berhasil ternyata mempunyai budaya yang kuat. O'Reilly Chatman dan Cadwell (1991) dalam penelitiannya bahwa budaya perusahaan mempunyai pengaruh terhadap efektifitas perusahaan, terutama pada perusahaan yang mempunyai budaya yang sesuai dengan strategi dan dapat meningkatkan komitmen karyawan terhadap perusahaan. Kesesuaian antara budaya organisasi terhadap partisipasi yang mendukungnya akan menimbulkan kepuasan kerja yang mendorong individu untuk kreatif dalam arti dapat meningkatkan kinerja perusahaan.

Survei yang dilakukan Sheridan (1992), menunjukkan bahwa budaya organisasi secara signifikan berhubungan positif dengan kinerja karyawan, voluntary turnover dan komitmen organisasi. Dikatakan bahwa variasi dalam cultural value 
memiliki pengaruh terhadap tingkat turnover dan kinerja karyawan. Indriantoro (2000), dalam Erni R. Ernawan (2004) menyatakan bahwa budaya organisasi merupakan topik yang penting, karena budaya organisasi merupakan assets tidak berwujud milik perusahaan. Budaya organisasi dianggap assets yang dapat meningkatkan kinerja organisasi. Budaya organisasi dalam hal ini selalu mempunyai dampak positif terhadap kehidupan perusahaan.

\section{Pengaruh Gaya Kepemimpinan terhadap Kinerja Karyawan}

Hasil analisis telah membuktikan terdapat pengaruh gaya kepemimpinan terhadap kinerja karyawan. Pengujian secara statistik membuktikan bahwa gaya kepemimpinan berpengaruh positif terhadap kinerja karyawan. Artinya bahwa ada pengaruh antara variabel gaya kepemimpinan terhadap kinerja karyawan di lingkungan kantor pusat Universitas Jember

Kepemimpinan pada dasarnya adalah proses mempengaruhi orang lain. Selain itu kepemimpinan juga berarti kemampuan untuk mempengaruhi, menggerakkan dan mengarahkan suatu tindakan pada diri seseorang atau sekelompok orang untuk tujuan tertentu. Dalam upaya mempengaruhi tersebut seorang pemimpin menerapkan gaya yang berbeda-beda dalam setiap situasi. Dimana menurut Stoner et. al (1996) gaya kepemimpinan (leadership styles) merupakan berbagai pola tingkah laku yang disukai oleh pemimpin dalam proses mengarahkan dan mempengaruhi pekerja. Dari pengertian tersebut terungkap bahwa apa yang dilakukan oleh atasan mempunyai pengaruh terhadap bawahan yang dapat membangkitkan semangat dan kegairahan kerja maupun sebaliknya.

Teori Path Goal dalam Yukl, (1989) mengatakan bahwa pemimpin mendorong kinerja yang lebih tinggi dengan cara memberikan kegiatan-kegiatan yang mempengaruhi bawahannya agar percaya bahwa hasil yang berharga bisa dicapai dengan usaha yang serius. Kepemimpinan yang berlaku secara universal menghasilkan tingkat kinerja dan kepuasan bawahan yang tinggi. Teori ini menyatakan bahwa situasi yang berbeda mensyaratkan gaya kepemimpinan yang berbeda. Bawahan dengan locus of control internal kepuasan kerjanya akan lebih tinggi dengan gaya kepemimpinan yang partisipatif sedangkan bawahan dengan locus of control eksternal kepuasan kerjanya akan lebih tinggi dengan gaya direktif.

Teori Path Goal menjelaskan tentang perilaku pemimpin gaya direktif, gaya suportif, gaya partisipatif, gaya pengasuh dan gaya orientasi prestasi mempengaruhi 
pengharapan ini. Sehingga mempengaruhi prestasi kerja bawahan dan kinerja bawahan. Dengan menggunakan salah satu dari empat gaya tersebut, seorang pemimpin harus berusaha untuk mempengaruhi persepsi para bawahan dan mampu memberikan motivasi kepada mereka tentang kejelasan-kejelasan tugasnya, pencapaian tujuan, kepuasan kerja dan pelaksanaan efektif (Griffin,1980 dalam Yukl, 1989).

Sejumlah penelitian tentang kepemimpinan telah menguji hubungan ini. Variable-variabel seperti gaya birokratis atau partisipatif, pusat kontrol, pengambilan risiko, usia dan latar belakang fungsional, serta penghargaan atau hukuman dari pimpinan telah ditelaah dalam kaitannya dengan kinerja dan perumusan strategi. Sementara Fiedler (1996, dalam Ogbonna dan Harris, 2000) membuktikan pentingnya efektifitas kepemimpinan dengan argumentasinya bahwa efektivitas seorang pemimpin merupakan determinan utama keberhasilan atau kegagalan kelompok, organisasi atau bahkan negara.

\section{Pengaruh Kepuasan Kerja terhadap Kinerja}

Hasil penelitian menunjukkan kepuasan kerja mempunyai pengaruh yang signifikan terhadap kinerja. Sehingga hipotesis yang menyatakan bahwa kepuasan kerja berpengaruh terhadap kinerja karyawan di lingkungan Kantor Pusat Universitas Jember terbukti kebenarannya atau $\mathrm{H} 5$ diterima.

Kepuasan kerja merupakan perasaan gembira atau positif yang dimiliki oleh dosen terhadap pekerjaan itu sendiri, ganjaran yang diterima ataupun perasaan yang berhubungan dengan dirinya. Karena itu maka kepuasan kerja menyangkut perasaan yang bukan berarti tidak perlu diperhatikan sebab kepuasan kerja akan tercermin pada hasil pekerjaan. Oleh karena itu, pimpinan sebagai manajer dituntut lebih profesional agar mampu menimbulkan kepuasan kerja pada dosen.

Semakin tinggi kepuasan kerja yang dicapai oleh karyawan maka akan meningkatkan kinerja karyawan. Hal itu disebabkan adanya kesan positif yang timbul pada karyawan akan menyebabkan adanya dorongan intrinsik untuk mencapai hasil kerja yang diharapkan akan optimal. Adanya hasil penelitian ini juga didukung dengan jawaban responden secara keseluruhan yang menunjukkan bahwa sebagian responden mempunyai persepsi sangat setuju tentang kinerja. Hal itu menunjukkan bahwa karyawan di lingkungan Kantor Pusat Universitas Jember mempunyai usaha dalam meningkatkan kinerja. Pengaruh langsung yang ditimbulkan oleh kepuasan 
terhadap kinerja karyawan pada tahap tersebut adanya kepuasan kerja yang dicapai karyawan akan berpengaruh secara langsung terhadap kinerja karyawan di lingkungan Kantor Pusat Universitas Jember.

\section{Kesimpulan}

Berdasarkan hasil analisis dan pembahasan yang telah dilakukan, maka dapat disimpulkan sebagai berikut: (1) Budaya organisasi berpengaruh signifikan terhadap kepuasan kerja karyawan di lingkungan kantor pusat Universitas Jember; (2) Gaya kepemimpinan berpengaruh signifikan terhadap kepuasan kerja karyawan di lingkungan kantor pusat Universitas Jember; (3) Budaya organisasi berpengaruh signifikan terhadap kinerja karyawan di lingkungan kantor pusat Universitas Jember; (4) Gaya kepemimpinan berpengaruh signifikan terhadap kinerja karyawan di lingkungan kantor pusat Universitas Jember; dan (5) Kepuasan kerja berpengaruh signifikan terhadap kinerja karyawan di lingkungan kantor pusat Universitas Jember.

\section{Saran}

Berdasarkan hasil pengujian, ketiganya berpengaruh positif terhadap kinerja karyawan. Dengan tingkat pengaruh dari yang tertinggi sampai dengan yang terendah masing-masing adalah kepuasan kerja, gaya kepemimpinan, dan budaya organisasi. Sehubungan dengan hal tersebut maka pihak kantor pusat Universitas Jember dapat memberikan perhatian terutama: (1) Kepuasan kerja bagi karyawan harus mendapat perhatian pihak manajemen kantor pusat Universitas Jember. Jika kepuasan kerja dapat diberikan maka diharapkan kepuasan kerja mereka meningkat akan memberikan kontribusi kerja yang lebih baik yang pada akhirnya ada peningkatan kinerja karyawan. Dalam hal ini terutama perhatian diarahkan pada usaha pihak pengelola terhadap perbaikan dimensi-dimensi kepuasan kerja. Sesuai dengan urutan prioritas berdasarkan besarnya pengaruh terhadap kepuasan kerja yang sepadan dengan pekerjaan, serta diberikan tunjangan-tunjangan yang lain; (2) Budaya organisasi sebagai prediktor kepuasan kerja dan kinerja karyawan. Oleh karena itu, budaya organisasi yang dibangun dapat memberikan ruang gerak perilaku karyawan yang lebih mendorong terhadap peningkatan kepuasan kerja karyawan. Dimensidimensi budaya organisasi, sesuai prioritas yang dapat diusahakan untuk ditingkatkan meliputi : konflik, profesionalisme, keteraturan, jarak dari manajemen, kepercayaan, integrasi; dan (3) Untuk mewujudkan gaya kepemimpinan yang bisa memberikan 
dukungan peningkatan kinerja, dapat diusahakan melalui dimensi - dimensi gaya kepemimpinan dengan urutan prioritas pengaruh masing - masing dimensi adalah sebagai berikut : pengaruh ideal, pengembangan intelektual, inspirasi, perhatian pribadi.

\section{Daftar Referensi}

Bluestone, Barry, and Irving Bluestone, 1992, Negotiating The Future: A Labor Prespective on American Business. New York: Basic Books.

Bonar M. Sinaga, 1994, Berbagai Metode Sampling, Metode Penelitian Sosial Ekonomi, Direktorat Perguruan Tinggi Swasta, Direktorat Jendral Pendidikan Tinggi, Jakarta.

Daulatram B. Lund 2003, "Organizational Culture ang Job Satisfaction", Journal of Business and Industrial Marketing, Vol. 18, No. 3.

Erni R. Ernawan, 2004, "Pengaruh Budaya Organisasi dan Orientasi Etika Terhadap Kinerja Perusahaan Manufaktur", Usahawan, September, No. 09, Tahun XXXIII.

Gibson J. H., Ivancevich J. M. \& Donnally Jr. J. H., 1991, Organization: Behaviour, Stucture, Processes, Homeword III: Richard D. Irwin, Inc.

Harris L.C., Ogbonna E, 2001, "Leadership Style and Market Orientation : An Empirical Study" , European Joumal of Marketing, 35,5/6

Harris S. G. \& Mossholder K. W, 1996, "The Effective Implication of Perceived Congruence with Cultural Dimensions During Organizational Transformation",Journal of Management, 22, 527-547.

Jackson S. E., 1983, "Participation in Decision-Making as a Strategy for Reducing JobRelated Strain", Journal of Applied Psychology 68(1): 3-19.

Kotter J.P. and Heskett J.L., 1992, Corporate Culture and Performance, The Free Press, New York.

Miller K. I., \& P.R. Monge, 1986, "Participation, Satisfaction, and Productivity: A MetaAnalytic Review", Academy of Management Journal 29(4): 727-53.

O' Reilly III C. A., Chatman J. Caldwell D. F., 1991, "People and Organizational Culture: A Profile Comparison Approach to Assessing Person - Organization Fit", Academy of Management Journal, Vol. 34, 3, p.487-516.

Robbins S. P.,2001, Perilaku Organisasi: Konsep, Kontroversi, Aplikasi, edisi kedelapan versi Bahasa Indonesia, Jilid 1 \& 2, PT Prenhallindo, Jakarta.

Shea Christine M, 199, "The Effect of Leadership Style on Performance Imptovement on a Manufacturing Task", Journal of Business, Vol 72, No. 3. 
Sheridan J.E (1992), "Organizational Culture and Employee Retention", Academy of Management Journal (Desember) PP 1036 - 1056.

Soonhee Kim, 2002, "Participative Management and Job Satisfaction : Lesson for Management Leadership", Public Administration Review, Vol 62, No. 2, P. 231 241.

Stoner James, DKK, 1996, Manajemen, Edisi Bahasa Indonesia, Penerbit PT. Prenhallindo, Jakarta.

Wallach E. J., 1983, "Individual and Organizations: The Culture Match", Training and Development Journal, 37: 2, 29-36.

Yukl, Gary A, 1989, Leadership in Organization, Second Edition, Prentice Hall International Inc. 